\title{
Leader's Interpersonal Skills and its Effectiveness at Different Levels of Management
}

\author{
Dr. R. Latha \\ Assistant Professor, KG College of Arts and Science, \\ Coimbatore, Tamil Nadu
}

\section{ABSTRACT}

This researcher examined Leader's Interpersonal aptitudes (Ability to Motivate, Communicate, and Build Team) also, its viability at various levels of Management. Writing demonstrated that these aptitudes are imperative to be powerful pioneer however it didn't demonstrate that which expertise is more essential at various levels of administration. For this reason poll was conveyed to 150 representatives in assorted divisions what's more, innovation incorporates Top level, Middle level and Lower level representatives. Clear trial of means and ANOVA were utilized as the most suitable factual systems to examine what ability is more essential at diverse levels of administration. The consequences of this examination found that at Top level of administration pioneer's capacity to Fabricate Team is more critical when contrasted with Middle level of administration however did not fundamentally vary as contrasted with Low level of administration. At Middle level speculation was not upheld (i.e. Capacity to Communicate was not most important to be effective at Middle level of administration). At Low level of administration pioneer's capacity to Motivate is more essential when contrasted with Middle level of administration yet did not altogether vary when contrasted with Top level of administration.

KEY WORDS: Ability to Motivate, Ability to Communicate, Ability to Build Team, Levels of Management

\section{INTRODUCTION}

As it is realized that Motivation, correspondence, and group building aptitudes are interrelated and reciprocal that is the reason initiative needs to advancement in these regions (Gilley, McMillan, and Gilley, 2009) So accordingly, for viable change improvement of relational aptitudes, for example, correspondence, inspiration, and group building is required to completely connect with representatives and to develop achievement.

Pioneers perform at various levels of administration, to be a compelling pioneer at Lower level, the pioneer must be able to inspire to complete the work in light of the fact that real work is done at this level of administration and furthermore it must be able to impart its specialists issues, proposals and recommendations, and so on to the larger amount. So at this level of administration (Low Level), Leaders capacity to persuade could really compare to that of correspondence and group building (Qureshi, 2009; Simmering, N.d..;Kraut, Pedigo, McKenna, and Dunnette., 1989).

At Middle level of administration, pioneers capacity to impart could easily compare to that of first level administration since it needs to complete two path correspondences; with lower level and with best administration. Center administrators impart upward, by offering recommendations and criticism to top chiefs additionally in charge of doing the objectives set by best administration (Simmering, N.d..;Kraut, et al., 1989). Furthermore Team building expertise is likewise required at center level of administration since it manufacture group which work at lower level and to complete work at lower administration inspiration ability is additionally required (Qureshi, 2009).Top administration generally comprises of Executives so they set out the expansive strategies and goals of the undertaking and for the most part includes arranging (Simmering, N.d.). Subsequently, the correspondence and inspiration are less required when contrasted with center administration (Qureshi, 
2009; Simmering, N.d.), so at Top administration Team building Skill is more essential since it's the Top administration that manufactured the group and controls them.

\section{OBJECTIVES OF THR STUDY}

The goal or reason for ebb and flow inquire about is to analyze how pioneer's Ability to Motivate, Communicate, and Build Team is vital at various levels of administration and which expertise of these three factors (the pioneer's Ability to Motivate, Communicate, and Build Teams) are more required at Top, Middle, and Lower levels of Management. As existing writing demonstrated that numerous factors (the pioneer's Ability to Motivate, Communicate, and Build Teams) influence a pioneer's viability and the writers additionally inspected practices which are related with authority adequacy for driving change (Gilley, McMillan, and Gilley, 2009); ebb and flow research will additionally upgrade our comprehension around: (a) The significance of pioneer's Ability to Motivate, Communicate, and Build Team at various levels of administration. (b) The levels of administration which are most needing change, in particular expertise/capacity territories, and the kind of progress which would demonstrate profitable. (c) How associations will improve the change aptitudes of their pioneers.

\section{LITERATURE REVIEW}

The Literature audit confirm that Leader's Interpersonal aptitudes, for example, pioneer's Ability to Motivate, Communicate, and Build Team positively affected authoritative change and Leadership adequacy. The following area talks about the Antecedents of authoritative change and initiative Effectiveness. Moreover it examines Linkage between pioneer's Ability to Motivate, Communicate, and Build Team and Leadership adequacy.

What's more, since the main role of this examination was to perceive how pioneer's Ability to Motivate, Communicate, and Build Team is critical at various levels of administration and what are the impacts of the levels of administration on hierarchical change and authority Effectiveness, in this way, the following areas portrayed the impacts of the predecessors of initiative viability and in addition the directing impact of levels of administration on authoritative change and administration Effectiveness. At last it talks about the impacts of each level of administration on pioneer's adequacy.
Predecessors of Organizational change and Leadership Effectiveness

Diverse elements that add to hierarchical change and authority Effectiveness are leader's Ability to Spur, Communicate, and Build Team. In an Association change did not happen except if its part gatherings and people change by receiving unique practices, forms, structures, schedules, qualities, or objectives (Coghlan, 2000; Katz and Kahn, 1966; Sullivan, Sullivan, and Buffton, 2002). So for successful Organizational change pioneer must have diverse aptitudes or practices, for example, pioneer's Ability to Motivate, Communicate, and Build Team (Gilley, McMillan, and Gilley, 2009), by embracing these abilities a Leader will turn into an Effective Leader. Furthermore, since the basic role of this investigation is to perceive how pioneer's Ability to Motivate, Communicate, what's more, Build Team is imperative at various levels of Management and what are the impacts of the levels of administration on hierarchical change and authority Effectiveness, in this manner, the following segments depicts the Linkage between pioneer's Ability to Motivate, Communicate, and Build Team and Leadership viability.

\subsubsection{Linkage between Ability to Communicate and Leadership Effectiveness}

On the off chance that Leader has Ability to Communicate well than he will be powerful pioneer and thus will bring positive change in an association (Gilley, McMillan, and Gilley, 2009). It is uncovered by the Research that there are extraly a few obstructions to change which incorporates the poor or absence of relational abilities, administration disappointment to remunerate those laborers who attempt to bring change, and the powerlessness to rouse or impact others (Burke, 1992; Kotter, 1996; Patterson, 1997). Studies demonstrated that there are certain pioneer's aptitudes and capacities which are positively connected with fruitful executeation of change, which incorporates the pioneer's capacities to mentor, impart, propel, include others, construct groups, and remunerate (Conner, 1992; Gill, 2003; Gilley, 2005; Sims, 2002; Ulrich, 1998). So by lacking great correspondence ability pioneer will be inadequate and won't have the capacity to cause viable change in an association. 


\subsubsection{Linkage between Ability to Motivate and Leadership Effectiveness}

Pioneer's Ability to Motivate is additionally of extraordinary significance to administration viability as that of pioneer's Ability to Communicate, if a pioneer can Motivate other people who are influencing his work than a pioneer will be viable pioneer (Gilley, McMillan, and Gilley, 2009), and will get constructive change an association. Numerous investigations (Burke, 1992; Gill, 2003; Gilley, 2005; Sims, 2002; Ulrich, 1998) appeared that there are sure pioneer's aptitudes and capacities which are emphatically connected with fruitful execution of progress, which incorporates the pioneer's capacities to mentor, impart, spur, include others, construct groups, and reward, so unmistakably there is a positive connection between pioneers capacity to inspire and administration viability.

\subsubsection{Linkage between Ability to assemble Team and Leadership Effectiveness}

Studies propose that pioneer's Abilities to Motivate, Communicate, and Build Teams will expand Leader's prosperity with change (Gilley, McMillan, and Gilley, 2009), so a Leader will be powerful on the off chance that he can manufacture and oversee group and will get positive change an association. Despite the fact that group building is critical for powerful Leadership yet it requires pioneers who can unmistakably (an) impart group objectives, choice, obligations and jobs, et cetera, (b) move and get certainty initiative assets and course, and (c) to rouse colleagues to determine diverse issues and to convey results (LaFasto and Larson, 2001), So to wind up powerful group building pioneer one must have the other two abilities i.e. Capacities to Motivate, Communicate.

Directing impact of Levels of Management on Leadership Effectiveness As it is realized that to be a successful pioneer and to get compelling change association, pioneer must have the Ability to Motivate, Communicate and Build Team (Gilley, McMillan, and Gilley, 2009), however these relational aptitudes might be contrastingly required at various levels of administration, which demonstrates that levels of administration affects authority viability. There are essentially three levels of Management i.e. Best, Middle and First level. At various levels of administration these aptitudes are diversely required and if a pioneer can accomplish these abilities as indicated by the prerequisites of each level than he/she will be compelling pioneer. The following area accordingly talks about the impact of each level of administration on initiative viability in detail.

\subsubsection{Top Level of Management and Leadership Effectiveness}

At Top level of administration pioneer for the most part includes in arranging procedure and sets hierarchical objectives and targets, they fundamentally don't immediate everyday exercises, accordingly at this level the capacity to spur and impart is less required when contrasted with different levels of administration (Qureshi, 2009; Simmering, N.d.), yet the significance of these relational abilities can't be dismissed contaminate without these relational aptitudes a pioneer can't be called a successful pioneer. Despite the fact that it isn't yet evident that which aptitudes is more critical for a pioneer to be powerful at Top level yet this demonstrates the connection between authority adequacy and best level of administration is a result of these relational abilities and a pioneer can't be compelling Top pioneer in the event that he/she doesn't can fabricate group so at Top administration Team building Skill is more vital in light of the fact that it's the best administration who manufactured the group and control them.

\subsubsection{Middle Level of Management and Leadership Effectiveness}

Numerous examinations (Simmering,N.d.; Kraut, et al., 1989) proposes that at Middle level of Management, pioneers Ability to Communicate could really compare to that of Top level administration since it needs to complete two route correspondence; with Lower level and with Top administration. At Middle level of administration, supervisor conveys upward, by offering proposals and input to top directors additionally in charge of completing the objectives set by best administration. Besides a few examinations (Qureshi, 2009) likewise proposes that Team building ability is additionally required at center level of administration since it manufacture group which work at lower level and to complete work at lower administration inspiration aptitude is additionally required. So by summing up it implies that like Top level of administration center level additionally expects capacity to inspire, convey and fabricate group yet in various extent and a pioneer must be successful center level pioneer on the off chance that he/she can rouse, impart and assemble group. This demonstrates linkage between center administration and authority adequacy is again a 
International Journal of Trend in Scientific Research and Development (IJTSRD) ISSN: 2456-6470

direct result of capacity to rouse, convey and construct group and a pioneer will be successful at center level in the event that he/she have these relational aptitudes.

\section{First Level of Management and Leadership Effectiveness}

At Lower level or First level of administration pioneer's Ability to Motivate, Communicate and Build Team is too essential as on other two levels of administration. At First - level of administration administrators have an extremely solid effect on the organization, despite the fact that typically they don't set objectives for the association however these supervisors for the most part collaborate with workers once a day, and if the administrators perform ineffectively, representatives may likewise perform inadequately which may cause absence of inspiration, or workers may leave the company (Stewing, N.d.). Numerous investigations (Qureshi, 2009; Stewing, N.d.; Kraut, et al., 1989) uncovered that at first level of administration pioneer must have the capacity to inspire to complete the work in light of the fact that genuine work is done at this level of administration. Secondly it must be able to impart its specialist's issues, proposals, and proposals and so forth to the more elevated amount. So at this level of administration, Leaders Ability to Motivate could really compare to that of Correspondence and Team working as compared to other two levels.

Convincingly at First level of administration pioneer's Ability to Motivate, Communicate and Build Team is likewise of incredible significance as on Top and Middle level of administration however these abilities are required at various extent, a few abilities are more required and a few are less required then others. Plainly there is additionally a connection between authority viability and First level of administration and it is on account of these relational aptitudes and a pioneer can't be effective First level pioneer on the off chance that he/she doesn't have the Capacity to Motivate, Communicate and Build Team.

\section{Method}

This research study was based on quantitative research technique. The research analyzed that to be an effective leader which skill (i.e. Ability to Motivate, Communicate and Build Team) is most important at different levels of management. The detail of each element of the research design adopted in this research is discussed below.

\subsection{Sample}

A sample of 150 professionals was selected by using proportional allocation and the same questionnaire was sent to the all types of employees. However, due to poor response and many reminders, only 90 questionnaires were received by the deadline of the study, giving a response rate of $60 \%$. The (Table 1) summarizes the sample statistics of Age and Gender cross tabulation. Among the total respondents, 81 were males $(90 \%)$ and 9 females $(10 \%)$.

\subsection{Measuring Instrument}

The primary data was collected through questionnaire. The questionnaire was based on five point Likertscales $($ Never $=1$, Infrequently $=2$, Sometimes $=3$, Frequently $=4$, Always $=5$ ), adopted from (Gilley, 2005; Gilley and Gilley, 2008). A tailored questionnaire, comprise of 50 questions i.e. 15 regarding Leader's Ability to motivate, 15 regarding Leader's Ability to Communicate and 15 regarding Leader's Ability to Build team, along with Few questions about demographic factors, was designed to collect the primary data.

\subsection{Appropriate Statistical Tests}

Through SPSS Statistical tests Descriptive, ANOVA, Frequency distribution and Cross table results were obtained to find that to be an effective leader which skill (i.e. ability to motivate, communicate and build team) is most important at different levels of management.

\section{Results}

Previous Section outlined the method used in the collection of data for this research as well as initial analysis of Demographic factors Age and gender through cross table. This Section will present the descriptive statistics of the sample and the results of hypotheses testing. The research study had used SPSS software to analyze the collected data. First of all, demographic variables are analyzed, and their descriptive statistics are calculated. After Demographics for hypothesis testing, descriptive statistics was calculated between levels of management and leader's Ability to Motivate, Communicate, and Build Teams. For further clarification ANOVA was conducted. 
Results of the study clearly showed that the second hypothesis was not supported but third and first hypothesis was partially supported.

\section{Discussion and Conclusion}

The research founded that if the leader improves his ability to motivate at Top level of Management than he will be more effective leader than that of Low and Middle levels of management; but the First hypothesis stated that the leader heaving greater Ability to Motivate would be more effective at Low level of Management as compared to Top and Middle levels of Management. So the first hypothesis was only partially supported although the literature (Qureshi, 2009; Simmering, N.d..; Kraut, et al., 1989) was in favour of first hypothesis. As results showed that leader heaving greater Ability to Motivate would be more effective at Low level of Management as compared to Middle level of Management but as compared to Top level of Management it hypothesis was not supported. There were many reasons due to which the result differed from the literature such as the sample was small, the response rate to questionnaire was poor and data was collected from one organization etc.

\section{References}

1. Burke, W. W. (1992), Organizational development: A process of learning and changing, Reading, MA: Addison-Wesley.

2. Coghlan, D. (2000), The inter level dynamics of systemic learning and change, Reflections, The SOL Journal, 2(2),67-71

3. Drucker, P. (1999), Management challenges for the 21st century, New York: HarperCollins. Gill, R. (2003), Change management -or change leadership?, Journal of Change Management, 3(4), 307-321 